\title{
Article \\ Genomic and Transcriptomic Analysis Reveals Cuticular Protein Genes Responding to Different Insecticides in Fall Armyworm Spodoptera frugiperda
}

\author{
Jia-Ying Zhu ${ }^{1,2, *}{ }^{10}, \mathrm{Lu} \mathrm{Li}^{1}{ }^{1}$, Kai-Ran Xiao ${ }^{1}$, Shu-Qi He ${ }^{3}$ and Fu-Rong Gui ${ }^{3, *}$ \\ 1 Key Laboratory of Forest Disaster Warning and Control of Yunnan Province, Southwest Forestry University, \\ Kunming 650224, China; lilu0612@outlook.com (L.L.); xkr@swfu.edu.cn (K.-R.X.) \\ 2 Key Laboratory for Forest Resources Conservation and Utilization in the Southwest Mountains of China, \\ Ministry of Education, Southwest Forestry University, Kunming 650224, China \\ 3 Yunnan Plateau Characteristic Agricultural Industry Research Institute, Yunnan Agricultural University, \\ Kunming 650201, China; shuqi_he@foxmail.com \\ * Correspondence: jyzhu@swfu.edu.cn (J.-Y.Z.); guifr@ynau.edu.cn (F.-R.G.)
}

Citation: Zhu, J.-Y.; Li, L.; Xiao, K.-R.; He, S.-Q.; Gui, F.-R. Genomic and Transcriptomic Analysis Reveals Cuticular Protein Genes Responding to Different Insecticides in Fall Armyworm Spodoptera frugiperda. Insects 2021, 12, 997. https://doi.org /10.3390/insects12110997

Academic Editor: Ralf Nauen

Received: 25 September 2021 Accepted: 3 November 2021 Published: 5 November 2021

Publisher's Note: MDPI stays neutral with regard to jurisdictional claims in published maps and institutional affiliations.

Copyright: (c) 2021 by the authors. Licensee MDPI, Basel, Switzerland. This article is an open access article distributed under the terms and conditions of the Creative Commons Attribution (CC BY) license (https:// creativecommons.org/licenses/by/ $4.0 /)$.
Simple Summary: The fall armyworm (FAW), Spodoptera frugiperda, is a notorious agricultural pest worldwide, causing great damage to a wide variety of crops. This pest exhibited a remarkable field-evolved resistance to multiple insecticides. According to the evidence, a few cuticular proteins (CPs) participate in the insecticide resistance of several insects. This study was designed to explore whether $\mathrm{CP}$ genes of the FAW exhibit functional roles in responding to insecticides stress. There are a set of $\mathrm{CP}$ genes significantly regulated in response to the exposure to different insecticides, implying that $\mathrm{CP}$ genes play an important role in the FAW against insecticides stress. The results inspire further functional validation of $\mathrm{CP}$ genes in FAWs to gain a better understanding of its resistance to insecticides.

Abstract: The fall armyworm (FAW), Spodoptera frugiperda, is a serious pest of crucial crops causing great threats to the food security of the world. It has evolved resistance to various insecticides, while the underlying molecular mechanisms remain largely unknown. Cuticular proteins (CPs), as primary components in cuticle, play an important role in insects' protection against environmental stresses. Few of them have been documented as participating in insecticide resistance in several insect species. In order to explore whether $\mathrm{CP}$ genes of the FAW exhibit a functional role in responding to insecticides stress, a total of 206 CPs, classified into eight families, were identified from the genome of the FAW through a homology-based approach coupled with manual efforts. The temporal expression profiles of all identified CP genes across developmental stages and their responses to 23 different insecticides were analyzed using the RNA-seq data. Expression profiling indicated that most of the $\mathrm{CP}$ genes displayed stage-specific expression patterns. It was found that the expression of $51 \mathrm{CP}$ genes significantly changed after $48 \mathrm{~h}$ exposure to 17 different insecticides. The expression of eight CP genes responding to four insecticides were confirmed by RT-PCR analysis. The results showed that their overall expression profiles were consistent with RNA-seq analysis. The findings provide a basis for further functional investigation of CPs implied in insecticide stress in FAW.

Keywords: Spodoptera frugiperda; cuticular protein; insecticides; expression pattern; transcriptome

\section{Introduction}

The fall armyworm (FAW), Spodoptera frugiperda (Lepidoptera: Noctuidae), is a notoriously destructive pest that feeds on more than 350 host plants, causing major damage to economically important crops such as corn, rice, cotton, sorghum, soybean and vegetables [1,2]. The FAW is native to tropical and subtropical regions of the Americas. In 2016, it was first reported as an invasive species in Africa [3]. Currently, it has spread to at 
least 64 nations from Africa, Asia and Australia (https: / /www.cabi.org/isc/fallarmyworm, accessed on 28 August 2021). Due to its bioecological aspects such as extreme polyphagy, high reproductive capacity, strong migratory behavior and rapid adult dispersion, the FAW poses a global threat to agricultural production and food security. For instance, FAWs have caused maize yield losses of 50\% from Africa and southern Asia since 2016 [4], and it was estimated to cause up to \$US13 billion per year in crop losses across sub-Saharan Africa [5]. Control of FAWs primarily depends on the use of genetically modified crops expressing Bacillus thuringiensis (Bt) toxins and synthetic insecticides [6]. However, the FAW has evolved resistance to Bt crops and a variety of chemical pesticides, including organophosphates, carbamates, pyrethroids, benzoylureas and spinosyns [7-9]. The molecular mechanism of resistance is becoming imperative to be investigated to provide insights into the development of resistance management strategies for the FAW.

Cuticular proteins (CPs) are critical constituents of the insect cuticle, the exoskeleton, as well as the cuticle lining the foregut, hindgut and tracheae. They can be classified into more than ten families according to their conserved protein sequence motifs. The most abundant family is known as CPs with the Rebers-Riddiford motif (CPR) that can be assigned into three subfamilies, RR-1, RR-2 and RR-3 [10,11]. The other families include CPAP analogous to peritrophins (CPAP1 and CPAP3), CPs with the Tweedle motif (CPT), CPF with a 44 aa consensus, CPFL (CPF-like) with a conserved C-terminal region similar to $\mathrm{CPF}$ but lacking the consensus, CPCFC with C-x (5)-C motifs repeated two or three times, CPs consisting of an 18 aa motif, alanine-rich CPs of low complexity (CPLCA), CPs of low complexity with two invariant glycine residues in the conserved domain (CPLCG), CPs of low complexity with an invariant tryptophan in the conserved domain (CPLCW), proline-rich CPs of low complexity (CPLCP), CPs with well-conserved cysteine residues (CPCFC), glycine rich CP (CPG), CPH comprised of hypothetical CPs and Apidermin restricted to Hymenoptera [11-14]. As one of the large and diverse families in insects, CPs usually account for about $1 \%$ of the protein coding genes in their genomes [15]. Due to the mixture of $\mathrm{CPs}$, they greatly contribute to determine the properties of the insect cuticles for defending against environmental stresses [16,17]. Previous reports have shown that the changed expression of $\mathrm{CP}$ genes is associated with the exposure to insecticides, indicating that CPs participate in insecticide resistance [18-21]. However, the precise roles served by $\mathrm{CPs}$ in response to insecticides remain largely unknown.

In this study, $\mathrm{CP}$ genes have been annotated based on the recently published chromosomelevel genome sequences of FAW [22,23]. They were classified with respect to the families described above and phylogenetically analyzed. We then used high-throughput RNAseq analysis to reveal diverse $\mathrm{CP}$ gene expression patterns across developmental stages and identify the differentially expressed $\mathrm{CP}$ genes in response to the treatment of 23 insecticides, followed by validation with a RT-PCR (real time polymerase chain reaction). Combined with genomic and transcriptomic analysis, candidate CP genes of the FAW that are modulated by insecticide exposure were revealed. The data obtained here are helpful for exploring the function of $\mathrm{CP}$ genes associated with insecticide stress in this pest.

\section{Materials and Methods}

\subsection{Gene Identification}

To exhaustively identify $\mathrm{CP}$ genes from FAWs, the corresponding protein sequences were retrieved from Acyrthosiphon pisum, Anopheles gambiae, Apis mellifera, Bombyx mori, Drosophila melanogaster, Manduca sexta, Pediculus humanus, Spodoptera litura and Tribolium castaneum $[12,15,24]$. They were used to search against two reported reference genomes of the FAW by Blast with an e-value cutoff of $\mathrm{e}^{-5}[22,23]$. The genomic data of the FAW were downloaded from InsectBase (http:/ / www.insect-genome.com/Sfru/, version WMCG01000000, accessed on 15 May 2021) and CNSA (CNGB Nucleotide Sequence Archive) (https://db.cngb.org/cnsa/, accessed on 23 May 2021) with accession no. CNP0000513. Additionally, putative CP genes were identified by seeking the genomic data based on Hidden Markov Models of different $\mathrm{CP}$ families by HMMER3 search 
(http://hmmer.janelia.org/, accessed on 23 May 2021) [24,25]. The redundant sequences were removed using the CD-HIT program. Then, all identified genes were corrected using the transcriptomic (RNA-seq) data (see below). Predicted CP genes were further classified into families using an online tool, CutProtFam-Pred (http:/ / bioinformatics.biol.uoa.gr/ CutProtFam-Pred/, accessed on 20 August 2021) with default parameters [15].

\subsection{Phylogenetic Tree Construction}

Phylogenetic analysis was performed using the corresponding protein sequence of $\mathrm{CP}$ genes of FAW, S. litura, B. mori and M. sexta. Amino acid sequences were aligned with MUSCLE in MEGA X [26]. A phylogenetic tree was constructed using the maximum likelihood (ML) method by FastTree 2.1.11 (http: / / microbesonline.org/fasttree, accessed on 26 July 2021) with SH-like 1000 support under the model of WGA and CAT [27]. Trees were visualized and colored using FigTree v1.4.4 (http:/ / tree.bio.ed.ac.uk/software/figtree/, accessed on 26 July 2021).

\subsection{Gene Expression Profiling}

RNA-seq data of the FAW from different developmental stages including 1st-6th instar larvae, pupae and adults of both sexes were downloaded from InsectBase (http: //www.insect-genome.com/Sfru/, accessed on 15 May 2021) [23], which can also be accessed at NCBI with the BioProject accession no. PRJNA590312. To gain the differentially expressed $\mathrm{CP}$ genes responding to different insecticides, transcriptomic data from the 3rd instar larvae of FAW exposed to 23 insecticides including four biological, ten single and nine mixed chemical insecticides were downloaded from CNSA (https://db.cngb.org/cnsa/, accessed on 23 May 2021) with accession no. CNP0001020 [22]. The detailed information of the pesticides can be obtained from Gui et al. [22]. These pesticides were commonly used in agricultural production. Based on these data, a pipeline implemented in TBtools was used to calculate the transcript abundance with the TPM/FPKM method [28]. Significantly differentially expressed CP genes were tested using DESeq2 [29]. Gene expression profiles were illustrated and hierarchically clustered using the HeatMap package in TBtools [28].

\subsection{RT-PCR Analysis}

FAW used in the experiments were a colony maintained in our lab. Its larvae were fed on corns. The 3rd larvae of the FAW exposed to four insecticides including 20\% dinotefuran soluble granules (P10), $33 \mathrm{~g} / \mathrm{L}$ avermectin and bifenthrin emulsifiable concentrate (P14), $40 \%$ bifenthrin and thiacloprid suspension concentrate (P16) and 35\% chlorantraniliprole water dispersible granule (P23) were treated as described by Gui et al. [22]. In brief, square pieces of corn leaves $(2 \times 2 \mathrm{~cm})$ were dipped into different insecticides according to the Insecticide Resistance Action Committee (2019) (https: / /irac-online.org/, accessed on 5 March 2019). They were put on moist filer paper in a Petri dish with a diameter of $10 \mathrm{~cm}$ for feeding the larvae of the FAW. Ten FAW larvae were added to each Petri dish. The larvae fed on the corn leaves dipped into solution was set as control. Corn leaf pieces were replaced at an interval of $12 \mathrm{~h}$. After 24 and $48 \mathrm{~h}$, ten surviving larvae were put together for one biological replicate. They were transferred into a $1.5 \mathrm{~mL}$ Eppendorf tube. After homogenization of samples in liquid nitrogen, their total RNA was extracted with TRIzol regent (Invitrogen, Carlsbad, CA, USA) according to the manufacturer's protocol. Its quantity and integrity were accessed by Nano Drop ND-1000 spectrophotometer (PeqLab, Erlangen, Germany) and 1\% formaldehyde agarose gel electrophoresis, respectively. An equal amount of 1 ug total RNA from each sample was used to synthesize cDNA using PrimeScript RT Reagent Kit with gDNA Eraser (TaKaRa, Dalian, China) following the manufacturer's protocol. A total of eight $\mathrm{CP}$ genes were selected for validating their expressions after exposure to the above four insecticides by RT-PCR with Dream Taq Green PCR Master mix (Thermo Fisher Scientific, Waltham, MA, USA). Gene-specific primers were designed based on their sequences derived from the genome of the FAW using Primer Premier 5. Actin genes were used as an internal reference gene for normalization. Primers 
used here were listed in Table S1. PCR conditions were as follow: $3 \mathrm{~min}$ at $95^{\circ} \mathrm{C}, 36$ cycles consisting of $95{ }^{\circ} \mathrm{C}$ for $30 \mathrm{~s}, 54^{\circ} \mathrm{C}$ for $30 \mathrm{~s}$ and $72{ }^{\circ} \mathrm{C}$ for $1 \mathrm{~min}$, followed by $72{ }^{\circ} \mathrm{C}$ for $10 \mathrm{~min}$. PCR products were viewed in 1\% agarose gel stained with Gel Red (Biosharp, Hefei, China).

\section{Results}

\subsection{Identification and Characterization of CP Genes}

A total of putative 206 CP genes were identified by searching against the FAW genome followed by manual confirmation and correction (Table 1 and Table S2). They were classified into eight families including RR, CPT, CPFL, CPLCA, CPCFC, CPAP, CPG and CPH, based on CutProtFam-Pred and phylogenetic analyses. Among them, CPR comprised 124 members and constitutes the largest CP family in the FAW, followed by CPG and CPH with 24 and 21 members, respectively. The CPR gene family consisted of three subfamilies including RR1, RR2 and RR3. For the RR-1 and RR-2 subfamilies, they had the largest number of genes with 54 and 69, respectively. On the basis of sequence similarity to the known RR-3 proteins, only one CP gene assigned into the RR-3 subfamily was identified in the FAW genome. Within the CPAP family, 13 and 8 genes were classified into CPAP1 and CPAP3 subfamilies, respectively. To compare the FAW CPs with S. litura, B. mori and $M$. sexta CPs, phylogenetic tree of major CP families or subfamilies was constructed separately (Figure 1). The results showed that RR-1 and RR-2 proteins were clearly separated. CPs from these four lepidopteran species were largely orthologous to each other, displaying an evolutional conservation. In most of the clades, each species had a similar number of genes. A FAW-specific clade was rare in the phylogenetic trees. Only several FAW-specific clades were observed in the RR-2 subfamily, indicating species specific gene expansions by duplication.

Table 1. Summary of the gene number of each cuticular protein family in Spodoptera frugiperda, S. litura, Bombyx mori and Manduca sexta.

\begin{tabular}{ccccc}
\hline Motif & S. frugiperda & ${\text { S. } \text { litura }^{\mathbf{a}}}$ & ${\text { B. } \text { mori }^{\mathbf{b}}}$ & ${\text { M. } \text { sexta }^{\mathbf{c}}}^{\text {RR-1 }}$ \\
RR-2 & 54 & 63 & 56 & 79 \\
RR-3 & 69 & 129 & 93 & 124 \\
CPT & 1 & 1 & 3 & 4 \\
CPF & 5 & 5 & 4 & 4 \\
CPFL & 0 & 1 & 1 & 1 \\
CPLCA & 7 & 7 & 4 & 6 \\
CPCFC & 3 & 4 & 2 & 0 \\
CPAP1 & 1 & 1 & 1 & 1 \\
CPAP3 & 13 & 13 & 14 & 15 \\
CPG & 8 & 9 & 9 & 10 \\
CPH & 24 & 28 & 29 & 0 \\
Total & 21 & 26 & 31 & 0 \\
\hline
\end{tabular}

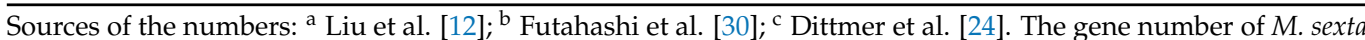
does not include the 18 aa family. 

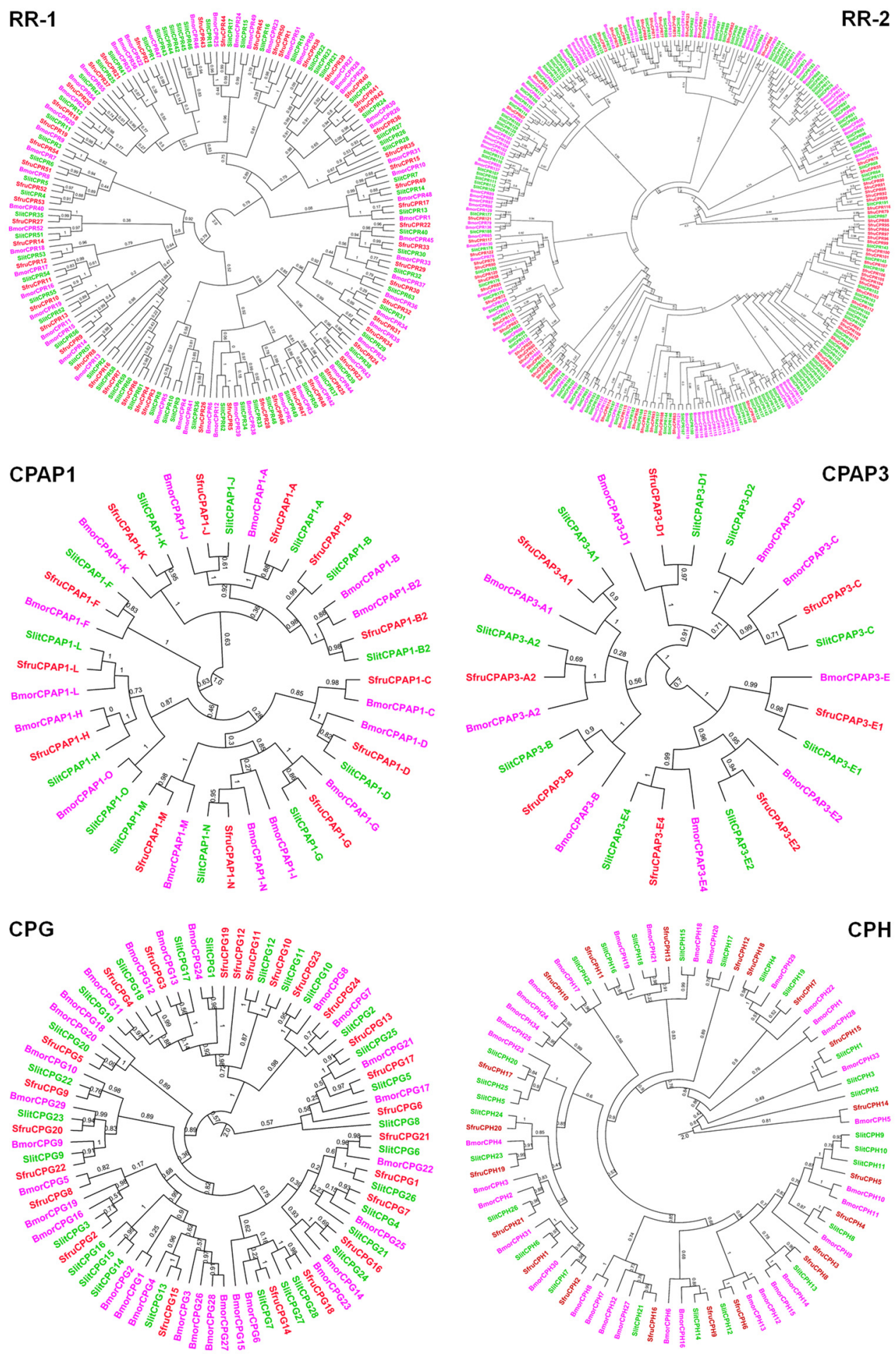

Figure 1. Maximum-likelihood tree of candidate CPs belonging to different families from four lepidopteran species. The tree was constructed by FastTree v2.1.11 (http:/ / microbesonline.org/ fasttree, accessed on 26 July 2021), based on an aligned amino acid sequence with MUSCLE in MEGA X. CPs marked by the same colors represents those from the same species. Bmor, Bombyx mori; Msex, Manduca sexta; Sfru, Spodoptera frugiperda; Slit, Spodoptera litura.

\subsection{CP Gene Expression across Developmental Stages}

The expression profiles of $\mathrm{CP}$ genes during FAW development were determined by using transcriptomic data from different developmental stages including 1st-6th instar larvae, pupa and adult (Table S3). There were ten CP genes with no TPM values observed 
for all samples, indicating that their expressions were not detected in this way. The expressions of other $\mathrm{CP}$ genes, represented by TPM values, were subjected to hierarchical clustering analysis. The results revealed that $\mathrm{CP}$ genes dynamically expressed across different developmental stages, represented by six distinct groups (Figure 2). More than half of the CP genes clustered into group A showed high expressions in 1st-3rd instar larvae. In this group, part of the $\mathrm{CP}$ genes also highly expressed in other stages. $\mathrm{CP}$ genes in groups B, C and D observed high expressions in the 2nd, 4th and 6th instar larvae, respectively. $\mathrm{CP}$ genes in group $\mathrm{E}$ highly expressed in pupae, part of which also showed high expression in the 4th instar larvae. In group F, CP gene expressions were abundant in adults, which were related to sex-biased expressions except for the SfruCPR29 gene. Additionally, CP genes that show sex-biased expressions can be found in other groups. Interestingly, most RR-1 genes expressed extremely highly at the larval stage, especially in the 1st-2nd instar larvae (Figures 2 and S1). Besides the 1st instar larvae, most RR-2 genes displayed stage-specific abundant expression at other stages. Additionally, stage-specific expression patterns were observed for some $\mathrm{CP}$ genes from other families. It should be noted that some $\mathrm{CP}$ genes from different families had high levels of expression at nearly all life stages, e.g., SfruCPR1, SfruCPAP3-E2 and SfruCPG2, which represents a small number of all CP genes.

A

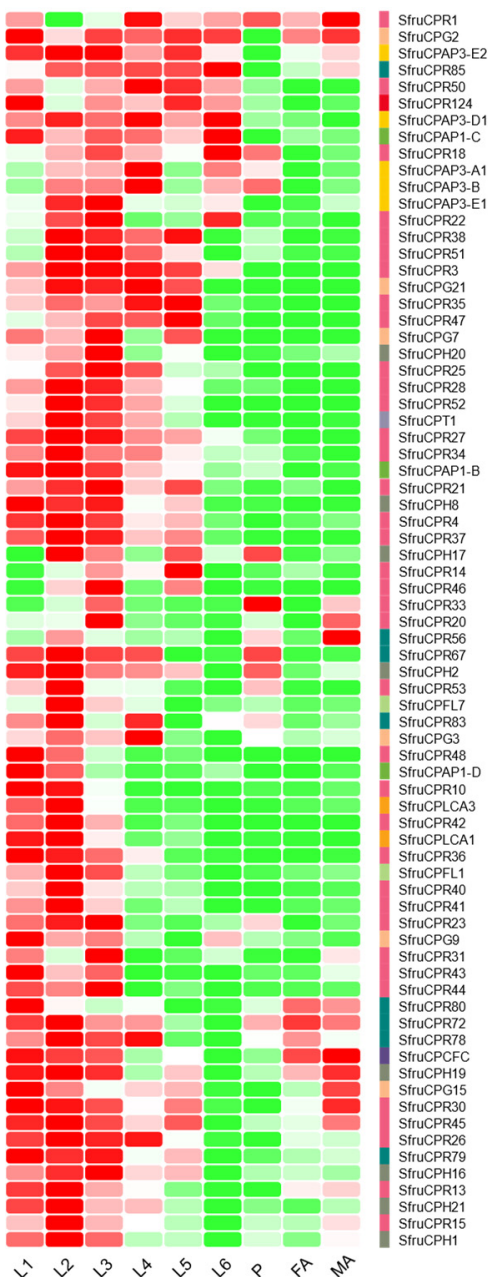

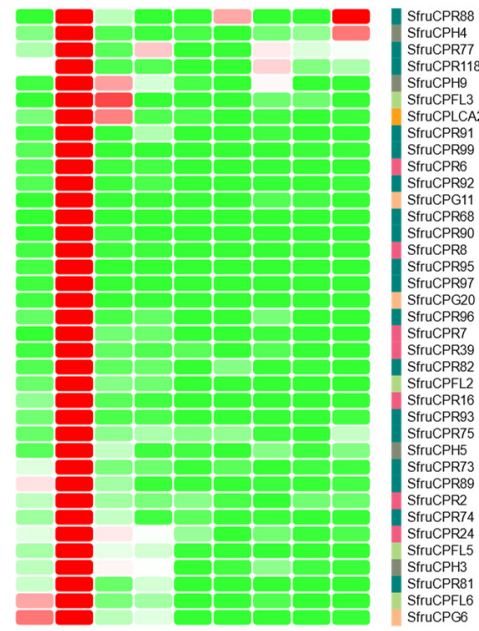

C

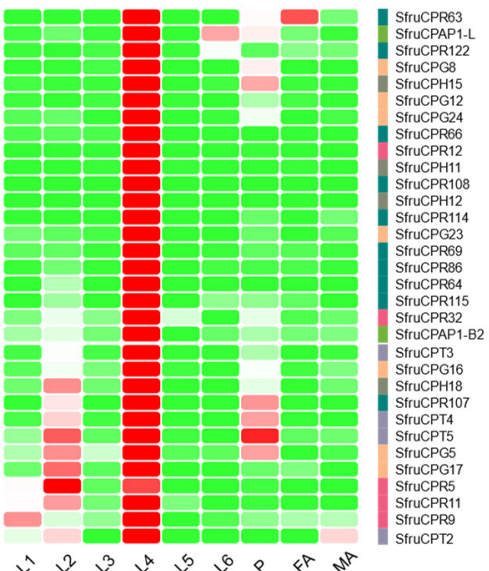

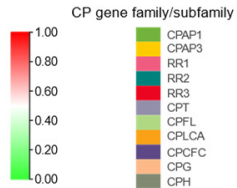

D

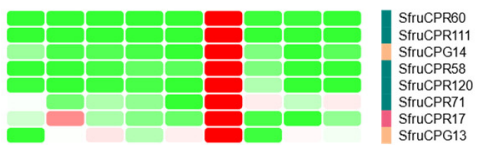

$E$
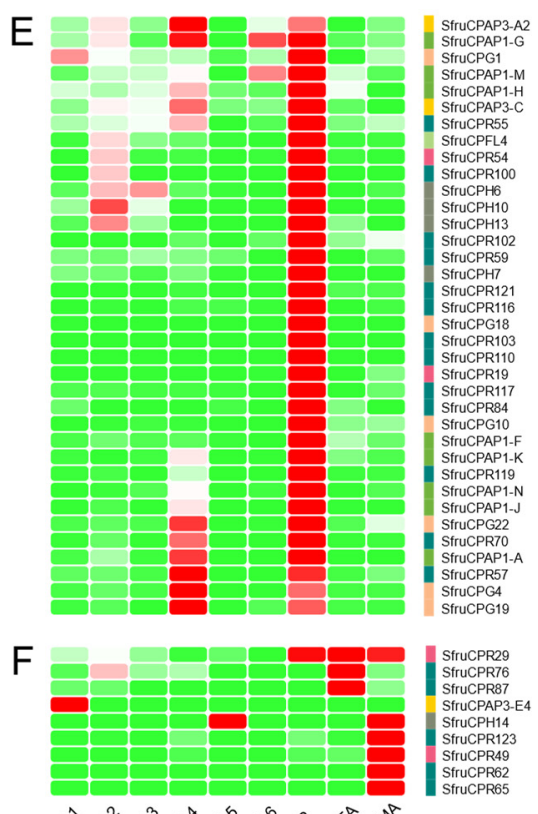

Figure 2. The expression profiles of CP genes across developmental stages. (A-F) highlight the hierarchically clustered $\mathrm{CP}$ genes with stage-specific expression patterns. The heat map was illustrated using the TPM values of CP transcripts calculated with the RNA-Seq data. Red and green indicate the high and low expressions, respectively. L1-L6: 1st-6th instar larvae; P, pupae; FA, female adult; MA, male adult. 


\subsection{Influence of Insecticides on CP Gene Expression}

By comparative transcriptome analysis, it was found that the expression of $51 \mathrm{CP}$ genes in the 3rd instar larvae of FAWs significantly changed after exposure to 23 insecticides in comparison to the control (Tables 2 and 3). The exposure of six insecticides did not influence the $\mathrm{CP}$ gene expression. The exposure of $\mathrm{P} 22$ led to the largest number of $\mathrm{CP}$ genes with changed expression, followed by P16 and P14. Among the differentially expressed $\mathrm{CP}$ genes, most of them displayed 4.38-26.64-fold down regulation (Figure 3). Seven (SfruCPR18, SfruCPR36, SfruCPR58, SfruCPG1, SfruCPG8, SfruCPG12 and SfruCPH15 genes) were defined as up regulated with the fold change ranging from 4.89 to 12.04 , which were induced by five insecticides. In order to validate the transcriptomic data, eight $\mathrm{CP}$ genes differentially expressed after exposure to four insecticides including P10, P14, P16 and P23, were selected for further verification using RT-PCR (Figures 4 and S2). Regarding those genes down regulated by P10, P14, P16 and P23 in RNA-Seq data, all CP genes were down regulated at $24 \mathrm{~h}$ post exposure to these insecticides. Besides SfruCPR32, SfruCPG16 and SfruCPT3 genes in the samples treated by P14 and P16, SfruCPG22 in samples treated by P16, and SfruCPG34 in samples treated by P10, the other CP genes were remarkably down regulated at $48 \mathrm{~h}$ after exposure to the above four insecticides, of which their overall expression profiles of $\mathrm{CP}$ genes were consistent with RNA-seq analysis.

Table 2. Differentially expressed CP genes of Spodoptera frugiperda after exposure to 23 insecticides.

\begin{tabular}{|c|c|c|c|c|}
\hline \multirow{2}{*}{ Insecticide Code } & \multirow{2}{*}{ Insecticide Treatment } & \multicolumn{3}{|c|}{ Differentially Expressed CP Gene } \\
\hline & & Up & Down & Total \\
\hline P1 & $\begin{array}{l}80 \text { billion spores/mL Metarhizium anisopliae suspension } \\
\text { concentrate }\end{array}$ & 0 & 0 & 0 \\
\hline $\mathrm{P} 2$ & 100 billion spores/g Bacillus thuringiensis suspension concentrate & 0 & 7 & 7 \\
\hline P3 & 100 billion spores/mL Empedobacter brevis suspension concentrate & 0 & 15 & 15 \\
\hline $\mathrm{P} 4$ & $0.3 \%$ azadirachtin emulsifiable concentrate & 0 & 4 & 4 \\
\hline P5 & $3 \%$ emamectin benzoate microemulsion & 0 & 0 & 0 \\
\hline P6 & $15 \%$ indoxacarb suspension concentrate & 0 & 1 & 1 \\
\hline P7 & $19 \%$ spinetoram water dispersible granule & 0 & 1 & 1 \\
\hline P8 & $10 \%$ chlorfenapyr suspension concentrate & 0 & 1 & 1 \\
\hline P9 & $10 \%$ ethofenprox suspension concentrate & 2 & 0 & 2 \\
\hline P10 & $20 \%$ dinotefuran soluble granules & 4 & 13 & 17 \\
\hline P11 & $25 \%$ cyhalodiamide and clothianidin suspension concentrate & 0 & 0 & 0 \\
\hline P12 & $8 \%$ avermectin and indoxacarb water dispersible granule & 0 & 17 & 17 \\
\hline P13 & $30 \%$ hexaflumuron and indoxacarb suspension concentrate & 0 & 11 & 11 \\
\hline P14 & $33 \mathrm{~g} / \mathrm{L}$ avermectin and bifenthrin emulsifiable concentrate & 0 & 23 & 23 \\
\hline P15 & $34 \%$ spinetoram and methoxyfenozide suspension concentrate & 0 & 3 & 3 \\
\hline P16 & $40 \%$ bifenthrin and thiacloprid suspension concentrate & 1 & 25 & 26 \\
\hline P17 & $10 \%$ emamectin and indoxacarb suspension concentrate & 0 & 0 & 0 \\
\hline P18 & $12 \%$ emamectin and flutolanil microemulsion & 0 & 0 & 0 \\
\hline P19 & $\begin{array}{l}40 \% \text { chlorantraniliprole and thiamethoxam water dispersible } \\
\text { granule }\end{array}$ & 0 & 0 & 0 \\
\hline P20 & $50 \mathrm{~g} / \mathrm{L}$ lufenuron emulsifiable concentrate & 4 & 1 & 5 \\
\hline P21 & $10 \%$ cyantraniliprole suspension concentrate & 4 & 4 & 8 \\
\hline $\mathrm{P} 22$ & $240 \mathrm{~g} / \mathrm{L}$ metaflumizone suspension concentrate & 0 & 29 & 29 \\
\hline P23 & $35 \%$ chlorantraniliprole water dispersible granule & 0 & 17 & 17 \\
\hline
\end{tabular}




\begin{tabular}{|c|c|c|c|}
\hline P2 & & P9 & \\
\hline-23.09 & SfruCPG4 & 10.73 & SfruCPH15 \\
\hline-22.21 & SfruCPG8 & 11.78 & SfruCPG8 \\
\hline-21.09 & SfruCPR113 & 11.78 & SfruCPG8 \\
\hline-21.09 & SfruCPR114 & -24.42 & SfruCPH13 \\
\hline-15.62 & SfruCPH7 & -24.37 & SfruCPR82 \\
\hline-8.84 & SfruCPG19 & -23.43 & SfruCPR39 \\
\hline-8.53 & SfruCPG22 & -23.43 & SfruCPR41 \\
\hline P3 & & -22.10 & SfruCPR90 \\
\hline-21.44 & SfruCPAP1-A & -8.74 & SfruCPH4 \\
\hline-18.45 & SfruCPG12 & -8.74 & SfruCPH5 \\
\hline-19.64 & SfruCPR113 & -8.13 & SfruCPR56 \\
\hline-19.64 & SfruCPR114 & -7.85 & SfruCPLCA2 \\
\hline-10.20 & SfruCPH13 & -5.91 & SfruCPR43 \\
\hline-9.80 & SfruCPR39 & -5.89 & SfruCPR11 \\
\hline-9.80 & SfruCPR41 & -4.76 & SfruCPLCA3 \\
\hline-9.72 & SfruCPR70 & -4.38 & SfruCPR34 \\
\hline-9.48 & SfruCPT3 & 5.62 & SfruCPR18 \\
\hline-8.98 & SfruCPR82 & 9.80 & SfruCPG12 \\
\hline-8.61 & SfruCPG22 & 10.96 & SfruCPH15 \\
\hline-8.52 & SfruCPT4 & 11.48 & SfruCPG8 \\
\hline-8.29 & SfruCPG16 & P12 & \\
\hline-8.11 & SfruCPLCA2 & -23.00 & SfruCPG4 \\
\hline-6.59 & SfruCPR32 & -21.21 & SfruCPG8 \\
\hline P4 & & -20.16 & SfruCPR113 \\
\hline-22.53 & SfruCPG8 & -20.16 & SfruCPR114 \\
\hline-21.20 & SfruCPR113 & -17.30 & SfruCPG20 \\
\hline-21.20 & SfruCPR114 & -14.91 & SfruCPH7 \\
\hline-15.71 & SfruCPH7 & -10.85 & SfruCPT4 \\
\hline P6 & & -10.73 & SfruCPR39 \\
\hline-15.77 & SfruCPH7 & -10.73 & SfruCPR41 \\
\hline P7 & & -10.65 & SfruCPH11 \\
\hline-20.10 & SfruCPG12 & -9.78 & SfruCPR82 \\
\hline P8 & & -9.40 & SfruCPH13 \\
\hline \multirow[t]{5}{*}{-15.90} & SfruCPH7 & -9.23 & SfruCPG22 \\
\hline & & -8.89 & SfruCPT3 \\
\hline & & -7.60 & SfruCPG16 \\
\hline & & -7.55 & SfruCPR32 \\
\hline & & -6.62 & SfruCPLCA2 \\
\hline
\end{tabular}

\begin{tabular}{|c|c|}
\hline P13 & \\
\hline-24.86 & SfruCPR39 \\
\hline-24.86 & SfruCPR41 \\
\hline-24.09 & SfruCPR9o \\
\hline-21.42 & SfruCPG23 \\
\hline-21.42 & SfruCPG24 \\
\hline-16.22 & SfruCPG20 \\
\hline-10.11 & SfruCPH13 \\
\hline-8.56 & SfruCPFL2 \\
\hline-7.10 & SfruCPR56 \\
\hline-6.74 & SfruCPR40 \\
\hline-6.08 & SfruCPR11 \\
\hline P14 & \\
\hline-25.89 & SfruCPR9o \\
\hline-25.33 & SfruCPH13 \\
\hline-24.09 & SfruCPR70 \\
\hline-21.72 & SfruCPAP1-A \\
\hline-21.09 & SfruCPG17 \\
\hline-20.69 & SfruCPG8 \\
\hline-19.74 & SfruCPR113 \\
\hline-19.74 & SfruCPR114 \\
\hline-19.11 & SfruCPH15 \\
\hline-16.99 & SfruCPG20 \\
\hline-10.08 & SfruCPR39 \\
\hline-10.08 & SfruCPR41 \\
\hline-9.98 & SfruCPR82 \\
\hline-9.70 & SfruCPT4 \\
\hline-8.67 & SfruCPT3 \\
\hline-8.33 & SfruCPR66 \\
\hline-8.33 & SfruCPR92 \\
\hline-8.15 & SfruCPR32 \\
\hline-7.97 & SfruCPG16 \\
\hline-7.66 & SfruCPG22 \\
\hline-6.97 & SfruCPR56 \\
\hline-5.77 & SfruCPR23 \\
\hline-5.69 & SfruCPR43 \\
\hline
\end{tabular}

\begin{tabular}{|c|c|}
\hline P15 & \\
\hline-21.79 & SfruCPR113 \\
\hline-21.79 & SfruCPR114 \\
\hline-19.62 & SfruCPG12 \\
\hline P16 & \\
\hline-26.64 & SfruCPR39 \\
\hline-26.64 & SfruCPR41 \\
\hline-26.37 & SfruCPR90 \\
\hline-24.25 & SfruCPR70 \\
\hline-23.22 & SfruCPG4 \\
\hline-21.95 & SfruCPAP1-A \\
\hline-20.18 & SfruCPR113 \\
\hline-20.18 & SfruCPR114 \\
\hline-11.35 & SfruCPH13 \\
\hline-10.46 & SfruCPR82 \\
\hline-9.69 & SfruCPT3 \\
\hline-8.44 & SfruCPT4 \\
\hline-8.36 & SfruCPLCA2 \\
\hline-7.99 & SfruCPG22 \\
\hline-7.78 & SfruCPR66 \\
\hline-7.78 & SfruCPR92 \\
\hline-7.27 & SfruCPR32 \\
\hline-7.21 & SfruCPG19 \\
\hline-7.04 & SfruCPG16 \\
\hline-6.72 & SfruCPR91 \\
\hline-6.72 & SfruCPR121 \\
\hline-6.72 & SfruCPR69 \\
\hline-6.72 & SfruCPR89 \\
\hline-5.65 & SfruCPR11 \\
\hline 4.89 & SfruCPR36 \\
\hline $\mathbf{P 2 0}$ & \\
\hline-21.16 & SfruCPAP1-A \\
\hline 5.29 & SfruCPR58 \\
\hline 8.14 & SfruCPR18 \\
\hline 8.70 & SfruCPG1 \\
\hline 9.10 & SfruCPH15 \\
\hline
\end{tabular}

\begin{tabular}{|c|c|}
\hline P21 & \\
\hline-24.04 & SfruCPH4 \\
\hline-24.04 & SfruCPH5 \\
\hline-23.05 & SfruCPR39 \\
\hline-23.05 & SfruCPR41 \\
\hline 6.70 & SfruCPR18 \\
\hline 8.21 & SfruCPG1 \\
\hline 10.84 & SfruCPH15 \\
\hline 12.04 & SfruCPG8 \\
\hline P22 & \\
\hline-25.03 & SfruCPH11 \\
\hline-22.95 & SfruCPG4 \\
\hline-22.10 & SfruCPG17 \\
\hline-20.45 & SfruCPR113 \\
\hline-20.45 & SfruCPR114 \\
\hline-20.18 & SfruCPR50 \\
\hline-17.49 & SfruCPG20 \\
\hline-15.12 & SfruCPH7 \\
\hline-10.80 & SfruCPG19 \\
\hline-9.80 & SfruCPR70 \\
\hline-9.63 & SfruCPR82 \\
\hline-9.50 & SfrucPT4 \\
\hline-9.37 & SfruCPLCA2 \\
\hline-8.96 & SfruCPG16 \\
\hline-8.92 & SfruCPG22 \\
\hline-8.56 & SfruCPH13 \\
\hline-8.24 & SfruCPR81 \\
\hline-7.80 & SfruCPT3 \\
\hline-7.21 & SfruCPR66 \\
\hline-7.21 & SfruCPR92 \\
\hline-6.79 & SfruCPR91 \\
\hline-6.79 & SfruCPR121 \\
\hline-6.79 & SfruCPR69 \\
\hline-6.79 & SfruCPR89 \\
\hline-6.59 & SfruCPR32 \\
\hline-5.82 & SfruCPR23 \\
\hline-5.39 & SfruCPR43 \\
\hline-5.36 & SfruCPR24 \\
\hline-5.36 & SfruCPR29 \\
\hline
\end{tabular}

\begin{tabular}{|l|l|l|}
\hline P23 & & \\
\hline-24.33 & SfruCPR39 & 15.00 \\
\hline-24.33 & SfruCPR41 & -10.00 \\
\hline-23.47 & SfruCPR90 & -00 \\
\hline-18.43 & SfruCPR113 & -00 \\
\hline-18.43 & SfruCPR114 & -10.00 \\
\hline-16.06 & SfruCPG20 & \\
\hline-15.00 \\
\hline-10.38 & SfruCPH13 \\
\hline-9.36 & SfruCPR82 \\
\hline-8.40 & SfruCPLCA2 \\
\hline-8.00 & SfruCPR40 \\
\hline-7.84 & SfruCPR66 \\
\hline-7.84 & SfruCPR92 \\
\hline-7.55 & SfruCPR56 \\
\hline-6.57 & SfruCPR32 \\
\hline-6.09 & SfruCPH3 \\
\hline-5.75 & SfruCPR43 \\
\hline-4.54 & SfruCPR34 \\
\hline
\end{tabular}

Figure 3. The detailed fold changes of $\mathrm{CP}$ genes after exposure to different insecticides. The detailed information of different insecticides corresponding to their codes (above the heat map) are represented in Table 2. Transcriptional levels were expressed as mean fold changes to the control. The red and green colors represent the up and down regulation of $\mathrm{CP}$ gene expression by different insecticides, respectively. The detailed fold change values on the left and the differentially expressed $\mathrm{CP}$ genes on the right are shown, which are below the insecticide codes. 


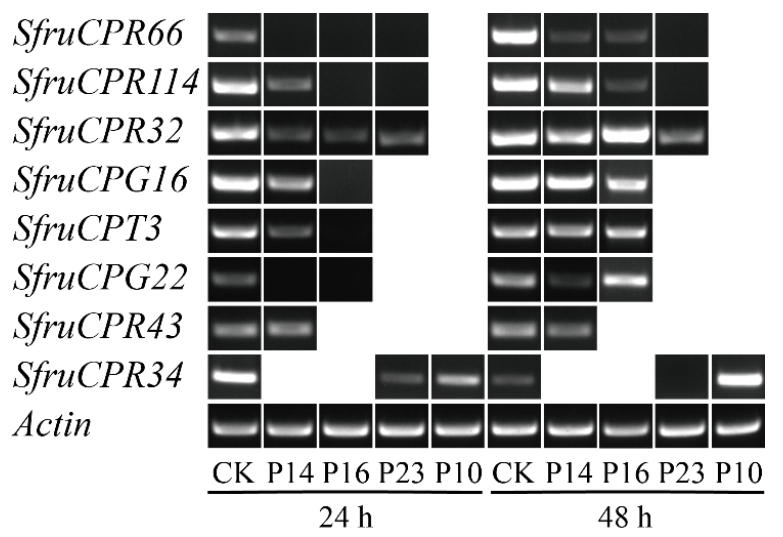

Figure 4. Relative expression level of eight candidate $\mathrm{CP}$ genes after exposure to four different insecticides. The expression of CPs was analyzed by RT-PCR. The actin gene was used as an internal reference. The detailed information of four different insecticides corresponding to their codes (P10, P14, P16 and P23) are represented in Table 2. The 3rd instar larvae of FAW exposed to different insecticides after $24 \mathrm{~h}$ and $48 \mathrm{~h}$ were used for RT-PCR analysis. CK represents no treatment of insecticides. It should be noted that if the expression of selected eight candidate $\mathrm{CP}$ genes do not change after exposure to these insecticides through RNA-seg analysis, their expressions are not further validated by RT-PCR analysis. Thus, the missing data for some treatments at each timepoint ( $24 \mathrm{~h}$ or $48 \mathrm{~h}$ after treatment) indicate that the CP gene expression was not validated by RT-PCR analysis.

Table 3. Detailed list of differentially expressed CP genes after exposure to different insecticides.

\begin{tabular}{|c|c|}
\hline Differentially Expressed CP Gene & Insecticide Code \\
\hline SfruCPR50, SfruCPR81, SfruCPR24, SfruCPR29 & $\mathrm{P} 22$ \\
\hline SfruCPR121, SfruCPR69, SfruCPR89, SfruCPR91 & P16, P22 \\
\hline SfruCPFL2, SfruCPG24, SfruCPG23 & $\mathrm{P} 13$ \\
\hline SfruCPG16, SfruCPT3, SfruCPT4 & P3, P12, P14, P16, P22 \\
\hline SfruCPH5, SfruCPH4 & P10, P21 \\
\hline SfruCPG17, SfruCPR23 & P14, P22 \\
\hline SfruCPR92, SfruCPR66 & P14, P16, P22, P23 \\
\hline SfruCPR41, SfruCPR39 & P3, P10, P12, P13, P14, P16, P21, P23 \\
\hline SfruCPR114, SfruCPR113 & $\mathrm{P} 2, \mathrm{P} 3, \mathrm{P} 4, \mathrm{P} 12, \mathrm{P} 14, \mathrm{P} 15, \mathrm{P} 16, \mathrm{P} 22, \mathrm{P} 23$ \\
\hline SfruCPLCA3 & $\mathrm{P} 10$ \\
\hline SfruCPR36 & P16 \\
\hline SfruCPR58 & P20 \\
\hline SfruCPH3 & P23 \\
\hline SfruCPR34 & $\mathrm{P} 10, \mathrm{P} 23$ \\
\hline SfruCPH11 & $\mathrm{P} 12, \mathrm{P} 22$ \\
\hline SfruCPR40 & $\mathrm{P} 13, \mathrm{P} 23$ \\
\hline SfruCPG1 & P20, P21 \\
\hline SfruCPG19 & $\mathrm{P} 2, \mathrm{P} 16, \mathrm{P} 22$ \\
\hline SfruCPR11 & P10, P13, P16 \\
\hline SfruCPR18 & P10, P20, P21 \\
\hline SfruCPG4 & P1, P12, P16, P22 \\
\hline SfruCPR56 & $\mathrm{P} 10, \mathrm{P} 13, \mathrm{P} 14, \mathrm{P} 23$ \\
\hline SfruCPR90 & $\mathrm{P} 10, \mathrm{P} 13, \mathrm{P} 14, \mathrm{P} 16, \mathrm{P} 23$ \\
\hline SfruCPR43 & $\mathrm{P} 10, \mathrm{P} 14, \mathrm{P} 22, \mathrm{P} 23$ \\
\hline SfruCPG12 & P3, P7, P10, P15 \\
\hline SfruCPAP1-A & $\mathrm{P} 3, \mathrm{P} 14, \mathrm{P} 16, \mathrm{P} 20$ \\
\hline SfruCPR70 & P3, P14, P16, P22 \\
\hline SfruCPH15 & P9, P10, P14, P20, P21 \\
\hline SfruCPG20 & P12, P13, P14, P22, P23 \\
\hline SfruCPG22 & $\mathrm{P} 2, \mathrm{P} 3, \mathrm{P} 12, \mathrm{P} 14, \mathrm{P} 16, \mathrm{P} 22$ \\
\hline SfruCPH7 & P2, P4, P6, P8, P12, P22 \\
\hline SfruCPLCA2 & P3, P10, P12, P16, P22, P23 \\
\hline SfruCPR32 & P3, P12, P14, P16, P22, P23 \\
\hline SfruCPG8 & $\mathrm{P} 2, \mathrm{P} 4, \mathrm{P} 9, \mathrm{P} 10, \mathrm{P} 12, \mathrm{P} 14, \mathrm{P} 21$ \\
\hline SfruCPR82 & $\mathrm{P} 3, \mathrm{P} 10, \mathrm{P} 12, \mathrm{P} 14, \mathrm{P} 16, \mathrm{P} 22, \mathrm{P} 23$ \\
\hline SfruCPH13 & $\mathrm{P} 3, \mathrm{P} 10, \mathrm{P} 12, \mathrm{P} 13, \mathrm{P} 14, \mathrm{P} 16, \mathrm{P} 22, \mathrm{P} 23$ \\
\hline
\end{tabular}


$\mathrm{CP}$ genes differentially expressed after exposure to different insecticides are listed in the left column. Different insecticides corresponding to their codes in Table 2 that lead to the change of $\mathrm{CP}$ gene expression are listed in the right column.

\section{Discussion}

The present report provides the first genome-wide identification of the $\mathrm{CP}$ gene families in the FAW, a voracious agricultural pest causing considerable economic costs [5]. The number of $\mathrm{CP}$ genes in FAWs was consistent with previous reports that they are generally comprised of around $1 \%$ of the genes encoding in the genome of insect species [15]. Compared with the number of $\mathrm{CP}$ genes in genomes of other lepidopteran species, $\mathrm{CP}$ genes carried by FAWs are lower than those in the genomes of S. litura, B. mori and $M$. sexta $[12,15,24,30]$. The CP gene number is significantly varied across insect species and taxa, ranging from 45 in A. mellifera to 305 in Aedes aegypti [31-33]. Interestingly, genomebased analysis revealed that 287 putative CPs were predicted in S. litura, a lepidopteran species closely related to the FAW [12]. The high number of annotated CPs in S. litura results in a large species-specific expansion of RR-1 and RR-2 CPs by gene duplication events. The number of $\mathrm{CP}$ genes in FAWs is obviously distinct from $S$. litura, suggesting a high rate of gene turnover between these two species. Similar to other reports, phylogenetic analysis of major $\mathrm{CP}$ families revealed that co-orthologous groups were present in FAW, S. litura, B. mori and M. sexta [12,24]. The orthologous CPs from different species clustered in a monophyletic clade are attributed to gene duplication events occurring after speciation $[24,34]$. It suggests that $\mathrm{CP}$ gene families evolved from an ancestral gene through duplication and diversification.

Hierarchical clustering analysis indicated that six clusters of $\mathrm{CP}$ genes with dynamic expression profiles were strikingly observed across developmental stages. Stage-specific expression of $\mathrm{CP}$ genes was also detected in other insects, such as Microplitis mediator, Bactrocera dorsalis, Dendrolimus punctatus and Nilaparvata lugens $[14,31,34,35]$. During larval to pupal development of FAWs, the expression pattern of the majority of $\mathrm{CP}$ genes had major changes. In addition, a much larger number of $\mathrm{CP}$ genes showed high expression in larvae and pupae than in adults. These should be due to the production of new cuticles associated with metamorphosis requiring large expression of $C P$ genes. Similar to $D$. punctatus, the majority of $\mathrm{CP}$ genes from different families were observed in high abundance at a specific life stage [34]. However, it is difficult to speculate whether the stage-specifically expressed $\mathrm{CP}$ genes entirely determine the cuticle formation during metamorphosis. Few $\mathrm{CP}$ genes were abundant in nearly all life stages, suggesting a significant role in general cuticle synthesis. It was documented that $\mathrm{CP}$ genes that displayed the most abundant expression in specific tissue at particular developmental stages played important roles associated with such tissues during specific developmental periods [12,14,24,31,33,34]. Thus, further investigation into unravelling the expression of $\mathrm{CP}$ genes between premolt/eclosion and post-molt/eclosion at particular developmental stages and multiple tissues is essential to provide deep insights into the functional perspectives of CPs in FAW.

As crucial components in insect cuticular, CPs functioned in environmental stresses such as insecticides, extreme temperature and ultraviolet by mediating cuticular permeability [17]. By comparative RNA-Seq analysis, it was revealed that the expression of CP genes was in response to exposure to six insecticides, suggesting a role in the adaption to some insecticides in FAWs. Similarly, CP genes responding to insecticides have been identified in a few insects. For example, the transcripts of two CPG genes (Ld-GRP1 and $L d-G R P 2)$ were highly induced by azinphosmethyl in adult of Leptinotarsa decemlineata [36]. Koganemaru et al. [37] found that many CPR genes were upregulated in pyrethroid resistant bed bug (Cimex lectularius). The expression of CPAP3-A1, CPAP3-C1, CPAP3-D1 and CPAP3-E2 genes were significantly induced in the oriental fruit fly (Bactrocera dorsalis) by malathion, the main pesticide used against this pest [31]. Interestingly, it has been documented that $C P$ genes were over-expressed in deltamethrin-resistant strains of $A$. sinensis and Culex pipiens pallens, and pyrethroid-resistant strains of A. stephensi, A. gambiae and A. sinensis [38-40]. 
This indicated that the upregulation of $\mathrm{CP}$ genes is linked to insecticide resistance, while only a few of them were evidenced as involved in such a role. For instance, the expression of the CPCPLCG5 gene in C. pipiens pallens was higher in the deltamethrin-resistant strain than in the susceptible strain [19], and knockdown of the CPCPLCG5 gene increased the susceptibility of the deltamethrin-resistant strain [41]. The over-expression of CP genes in resistant strains led to the increased thickness of cuticle, resulting in a cuticular penetration resistance to insecticide. Due to $\mathrm{CP}$ genes that exhibit higher expressions in resistant strains than in susceptible strains with the most potential to be implicated in insecticide resistance $[19,21,36,42], C P$ genes of FAW up regulated here are worth being focused on to investigate their role in insecticide resistance. In addition to induction, $\mathrm{CP}$ genes can also be reduced by insecticides. It is similar to detoxifying enzyme genes such as cytochrome P450, glutathione S-transferase and carboxylesterase genes being down regulated by insecticides, while the exact roles of the suppressed detoxification enzyme genes in insecticide resistance remain largely unknown [43]. For instance, among the $68 \mathrm{CP}$ genes differentially expressed after 6, 24 and $48 \mathrm{~h}$ exposure to permethrin in A. stephensi, part of them were down regulated [44]. Since silencing or mutation of CP genes can influence the development, and lead to the reduction of resistance to environmental stresses including insecticides [17,35], the reduced expression of $\mathrm{CP}$ genes would enhance the penetrability of insecticides by decreasing the thickness of cuticle. The CP genes associated with down-regulated expressions in FAWs could deserve to be potential candidates for further investigation of their important role in response to insecticide stress.

\section{Conclusions}

Genome-wide analysis with exhaustive homology-based searches and manual efforts in FAWs led to the identification of $206 \mathrm{CP}$ genes. Their expression profiles during different development time points and in response to the exposure of 23 different insecticides were investigated. A set of them, presumed to be responsive to a range of insecticides, were identified and validated using RT-PCR analysis. Our results provide insights for the further functional investigation of CP genes of FAW involved in insecticide stress.

Supplementary Materials: The following are available online at https:/ /www.mdpi.com/article/10 .3390/insects12110997/s1: Table S1: RT-PCR primers used in this study; Table S2: List of CP genes identified in the FAW genome; Table S3: TMP values of CP genes of FAWs at different developmental stages obtained from the RNA-seq data; Figure S1: The expression profiles of CP genes from different families or subfamilies at different developmental stages. The heat map was illustrated using the TPM values of CP transcripts calculated with the RNA-Seq data. Red indicates the high expression and green indicates the low expression; Figure S2: Validation of expression profiles of CP genes after exposure to four different insecticides by RT-PCR. The expression data represent the quantification of the band in Figure 4 from each sample, which have been normalized to the reference gene, actin. The data was statistically analyzed using the SPSS program.

Author Contributions: Conceptualization, J.-Y.Z. and F.-R.G.; investigation, J.-Y.Z., L.L., K.-R.X. and S.-Q.H.; methodology, J-Y.Z., L.L. and K.-R.X.; software, J.-Y.Z., L.L., K.-R.X.; formal analysis, J.-Y.Z., L.L., K.-R.X. and S.-Q.H.; visualization, J.-Y.Z., L.L. and K.-R.X.; supervision, J.-Y.Z.; project administration, J.-Y.Z.; funding acquisition, J.-Y.Z. and F.-R.G.; writing —original draft preparation, J.-Y.Z.; writing - review and editing, J.-Y.Z. and F.-R.G. All authors have read and agreed to the published version of the manuscript.

Funding: This work was supported by the Yunnan Eco-friendly Food International Cooperation Research Center (YEFICRC) Project of Yunnan Provincial Key Programs (Grant No. 2019ZG00910-01), and the Yunnan Provincial High-Level Talents Support Program (YNWR-QNBJ-2018-393).

Institutional Review Board Statement: Not applicable.

Informed Consent Statement: Not applicable.

Data Availability Statement: The data presented in this study are available in the Supplementary Materials section. 
Conflicts of Interest: The authors declare no conflict of interest.

\section{References}

1. Dumas, P.; Legeai, F.; Lemaitre, C.; Scaon, E.; Orsucci, M.; Labadie, K.; Gimenez, S.; Clamens, A.L.; Henri, H.; Vavre, F.; et al. Spodoptera frugiperda (Lepidoptera: Noctuidae) host-plant variants: Two host strains or two distinct species? Genetica 2015, 143, 305-316. [CrossRef]

2. Montezano, D.G.; Specht, A.; Sosa-Gómez, D.R.; Roque-Specht, V.F.; Sousa-Silva, J.C.; Paula-Moraes, S.V.; Peterson, J.A.; Hunt, T.E. Host plants of Spodoptera frugiperda (Lepidoptera: Noctuidae) in the Americas. Afr. Entomol. 2018, 26, 286-300. [CrossRef]

3. Goergen, G.; Kumar, P.L.; Sankung, S.B.; Togola, A.; Tamò, M. First report of outbreaks of the fall armyworm Spodoptera frugiperda (J E Smith) (Lepidoptera, Noctuidae), a new alien invasive pest in west and central Africa. PLoS ONE 2016, 11, e0165632. [CrossRef]

4. Silver, A. China seeks predator to stop voracious caterpillar. Nature 2019, 570, 286-287. [CrossRef] [PubMed]

5. Harrison, R.D.; Thierfelder, C.; Baudron, F.; Chinwada, P.; Midega, C.; Schaffner, U.; van den Berg, J. Agro-ecological options for fall armyworm (Spodoptera frugiperda JE Smith) management: Providing low-cost, smallholder friendly solutions to an invasive pest. J. Environ. Manag. 2019, 243, 318-330. [CrossRef] [PubMed]

6. Burtet, L.M.; Bernardi, O.; Melo, A.A.; Pes, M.P.; Strahl, T.T.; Guedes, J.V. Managing fall armyworm, Spodoptera frugiperda (Lepidoptera: Noctuidae), with Bt maize and insecticides in southern Brazil. Pest. Manag. Sci. 2017, 73, 2569-2577. [CrossRef]

7. Boaventura, D.; Ulrich, J.; Lueke, B.; Bolzan, A.; Okuma, D.; Gutbrod, O.; Geibel, S.; Zeng, Q.; Dourado, P.M.; Martinelli, S.; et al. Molecular characterization of Cry1F resistance in fall armyworm, Spodoptera frugiperda from Brazil. Insect Biochem. Mol. Biol. 2020, 116, 103280. [CrossRef] [PubMed]

8. Guan, F.; Zhang, J.; Shen, H.; Wang, X.; Padovan, A.; Walsh, T.K.; Tay, W.T.; Gordon, K.H.J.; James, W.; Czepak, C.; et al. Whole-genome sequencing to detect mutations associated with resistance to insecticides and Bt proteins in Spodoptera frugiperda. Insect Sci. 2021, 28, 627-638. [CrossRef]

9. Lira, E.C.; Bolzan, A.; Nascimento, A.R.; Amaral, F.S.; Kanno, R.H.; Kaiser, I.S.; Omoto, C. Resistance of Spodoptera frugiperda (Lepidoptera: Noctuidae) to spinetoram: Inheritance and cross-resistance to spinosad. Pest. Manag. Sci. 2020, 76, 2674-2680. [CrossRef]

10. Rebers, J.E.; Riddiford, L.M. Structure and expression of a Manduca sexta larval cuticle gene homologous to Drosophila cuticle genes. J. Mol. Biol. 1988, 203, 411-423. [CrossRef]

11. Willis, J.H.; Papandreou, N.C.; Iconomidou, V.A.; Hamodrakas, S.J. Cuticular proteins. In Insect Molecular Biology and Biochemistry Gilbert, L., Ed.; Elsevier: Amsterdam, The Netherlands, 2012; pp. 134-166.

12. Liu, J.; Li, S.; Li, W.; Peng, L.; Chen, Z.; Xiao, Y.; Guo, H.; Zhang, J.; Cheng, T.; Goldsmith, M.R.; et al. Genome-wide annotation and comparative analysis of cuticular protein genes in the noctuid pest Spodoptera litura. Insect Biochem. Mol. Biol. 2019, 110, 90-97. [CrossRef]

13. Willis, J.H. Structural cuticular proteins from arthropods: Annotation, nomenclature, and sequence characteristics in the genomics era. Insect Biochem. Mol. Biol. 2010, 40, 189-204. [CrossRef] [PubMed]

14. Volovych, O.; Lin, Z.; Du, J.; Jiang, H.; Zou, Z. Identification and temporal expression profiles of cuticular proteins in the endoparasitoid wasp, Microplitis mediator. Insect Sci. 2020, 27, 998-1018. [CrossRef]

15. Ioannidou, Z.S.; Theodoropoulou, M.C.; Papandreou, N.C.; Willis, J.H.; Hamodrakas, S.J. CutProtFam-Pred: Detection and classification of putative structural cuticular proteins from sequence alone, based on profile hidden Markov models. Insect Biochem. Mol. Biol. 2014, 52, 51-59. [CrossRef]

16. Andersen, S.O. Cuticular Sclerotization and Tanning. In Insect Molecular Biology and Biochemistry; Gilbert, L.I., Ed.; Academic Press: Cambridge, MA, USA, 2012; pp. 167-192.

17. Xiong, G.; Tong, X.; Yan, Z.; Hu, H.; Duan, X.; Li, C.; Han, M.; Lu, C.; Dai, F. Cuticular protein defective Bamboo mutant of Bombyx mori is sensitive to environmental stresses. Pestic. Biochem. Physiol. 2018, 148, 111-115. [CrossRef]

18. Chen, E.H.; Duan, J.Y.; Song, W.; Wang, D.X.; Tang, P.A. RNA-seq analysis reveals mitochondrial and cuticular protein genes are associated with phosphine resistance in the rusty grain beetle (Coleoptera: Laemophloeidae). J. Econ. Entomol. 2021, 114, 440-453. [CrossRef] [PubMed]

19. Huang, Y.; Guo, Q.; Sun, X.; Zhang, C.; Xu, N.; Xu, Y.; Zhou, D.; Sun, Y.; Ma, L.; Zhu, C.; et al. Culex pipiens pallens cuticular protein CPLCG5 participates in pyrethroid resistance by forming a rigid matrix. Parasit. Vectors 2018, 11, 6. [CrossRef] [PubMed]

20. Vannini, L.; Reed, T.W.; Willis, J.H. Temporal and spatial expression of cuticular proteins of Anopheles gambiae implicated in insecticide resistance or differentiation of M/S incipient species. Parasit. Vectors 2014, 7, 24. [CrossRef]

21. Xu, Y.; Yang, X.; Sun, X.; Li, X.; Liu, Z.; Yin, Q.; Ma, L.; Zhou, D.; Sun, Y.; Shen, B.; et al. Transcription factor FTZ-F1 regulates mosquito cuticular protein CPLCG5 conferring resistance to pyrethroids in Culex pipiens pallens. Parasit. Vectors 2020, 13, 514. [CrossRef]

22. Gui, F.; Lan, T.; Zhao, Y.; Guo, W.; Dong, Y.; Fang, D.; Liu, H.; Li, H.; Wang, H.; Hao, R.; et al. Genomic and transcriptomic analysis unveils population evolution and development of pesticide resistance in fall armyworm Spodoptera frugiperda. Protein Cell 2020. [CrossRef] [PubMed] 
23. Xiao, H.; Ye, X.; Xu, H.; Mei, Y.; Yang, Y.; Chen, X.; Yang, Y.; Liu, T.; Yu, Y.; Yang, W.; et al. The genetic adaptations of fall armyworm Spodoptera frugiperda facilitated its rapid global dispersal and invasion. Mol. Ecol. Resour. 2020, 20, 1050-1068. [CrossRef] [PubMed]

24. Dittmer, N.T.; Tetreau, G.; Cao, X.; Jiang, H.; Wang, P.; Kanost, M.R. Annotation and expression analysis of cuticular proteins from the tobacco hornworm, Manduca sexta. Insect Biochem. Mol. Biol. 2015, 62, 100-113. [CrossRef] [PubMed]

25. Mistry, J.; Finn, R.D.; Eddy, S.R.; Bateman, A.; Punta, M. Challenges in homology search: HMMER3 and convergent evolution of coiled-coil regions. Nucleic Acids Res. 2013, 41, e121. [CrossRef] [PubMed]

26. Kumar, S.; Stecher, G.; Li, M.; Knyaz, C.; Tamura, K. MEGA X: Molecular evolutionary genetics analysis across computing platforms. Mol. Biol. Evol. 2018, 35, 1547-1549. [CrossRef]

27. Price, M.N.; Dehal, P.S.; Arkin, A.P. FastTree: Computing large minimum evolution trees with profiles instead of a distance matrix. Mol. Biol. Evol. 2009, 26, 1641-1650. [CrossRef] [PubMed]

28. Chen, C.; Chen, H.; Zhang, Y.; Thomas, H.R.; Frank, M.H.; He, Y.; Xia, R. TBtools: An integrative toolkit developed for interactive analyses of big biological data. Mol. Plant 2020, 13, 1194-1202. [CrossRef] [PubMed]

29. Love, M.I.; Huber, W.; Anders, S. Moderated estimation of fold change and dispersion for RNA-seq data with DESeq2. Genome Biol. 2014, 15, 550. [CrossRef]

30. Futahashi, R.; Okamoto, S.; Kawasaki, H.; Zhong, Y.S.; Iwanaga, M.; Mita, K.; Fujiwara, H. Genome-wide identification of cuticular protein genes in the silkworm, Bombyx mori. Insect Biochem. Mol. Biol. 2008, 38, 1138-1146. [CrossRef]

31. Chen, E.H.; Hou, Q.L.; Dou, W.; Wei, D.D.; Yue, Y.; Yang, R.L.; Yang, P.J.; Yu, S.F.; De Schutter, K.; Smagghe, G.; et al. Genome-wide annotation of cuticular proteins in the oriental fruit fly (Bactrocera dorsalis), changes during pupariation and expression analysis of CPAP3 protein genes in response to environmental stresses. Insect Biochem. Mol. Biol. 2018, 97, 53-70. [CrossRef]

32. Liu, B.Q.; Qiao, L.; He, Q.Y.; Zhou, Y.; Ren, S.; Chen, B. Genome-wide identification, characterization and evolution of cuticular protein genes in the malaria vector Anopheles sinensis (Diptera: Culicidae). Insect Sci. 2018, 25, 739-750. [CrossRef]

33. Wang, J.; Jin, H.; Yang, L.; Ye, X.; Xiao, S.; Song, Q.; Stanley, D.; Ye, G.; Fang, Q. Genome-wide identification and analysis of genes encoding cuticular proteins in the endoparasitoid wasp Pteromalus puparum (Hymenoptera: Pteromalidae). Arch. Insect Biochem. Physiol. 2020, 103, e21628. [CrossRef]

34. Yang, C.H.; Yang, P.C.; Zhang, S.F.; Shi, Z.Y.; Kang, L.; Zhang, A.B. Identification, expression pattern, and feature analysis of cuticular protein genes in the pine moth Dendrolimus punctatus (Lepidoptera: Lasiocampidae). Insect Biochem. Mol. Biol. 2017, 83, 94-106. [CrossRef]

35. Pan, P.L.; Ye, Y.X.; Lou, Y.H.; Lu, J.B.; Cheng, C.; Shen, Y.; Moussian, B.; Zhang, C.X. A comprehensive omics analysis and functional survey of cuticular proteins in the brown planthopper. Proc. Natl. Acad. Sci. USA 2018, 115, 5175-5180. [CrossRef] [PubMed]

36. Zhang, J.; Goyer, C.; Pelletier, Y. Environmental stresses induce the expression of putative glycine-rich insect cuticular protein genes in adult Leptinotarsa decemlineata (Say). Insect Mol. Biol. 2008, 17, 209-216. [CrossRef] [PubMed]

37. Koganemaru, R.; Miller, D.M.; Adelman, Z.N. Robust cuticular penetration resistance in the common bed bug (Cimex lectularius L.) correlates with increased steady-state transcript levels of CPR-type cuticle protein genes. Pest. Biochem. Physiol. 2013, 106, 190-197. [CrossRef]

38. Awolola, T.S.; Oduola, O.A.; Strode, C.; Koekemoer, L.L.; Brooke, B.; Ranson, H. Evidence of multiple pyrethroid resistance mechanisms in the malaria vector Anopheles gambiae sensu stricto from Nigeria. Trans. R. Soc. Trop. Med. Hyg. 2009, 103, 1139-1145. [CrossRef] [PubMed]

39. Vontas, J.; David, J.P.; Nikou, D.; Hemingway, J.; Christophides, G.K.; Louis, C.; Ranson, H. Transcriptional analysis of insecticide resistance in Anopheles stephensi using cross-species microarray hybridization. Insect Mol. Biol. 2007, 16, 315-324. [CrossRef]

40. Zhou, D.; Duan, B.; Sun, Y.; Ma, L.; Zhu, C.; Shen, B. Preliminary characterization of putative structural cuticular proteins in the malaria vector Anopheles sinensis. Pest Manag. Sci. 2017, 73, 2519-2528. [CrossRef]

41. Fang, F.; Wang, W.; Zhang, D.; Lv, Y.; Zhou, D.; Ma, L.; Shen, B.; Sun, Y.; Zhu, C. The cuticle proteins: A putative role for deltamethrin resistance in Culex pipiens pallens. Parasitol. Res. 2015, 114, 4421-4429. [CrossRef]

42. Sun, X.; Guo, J.; Ye, W.; Guo, Q.; Huang, Y.; Ma, L.; Zhou, D.; Shen, B.; Sun, Y.; Zhu, C. Cuticle genes CpCPR63 and CpCPR47 may confer resistance to deltamethrin in Culex pipiens pallens. Parasitol. Res. 2017, 116, 2175-2179. [CrossRef]

43. Jia, Z.Q.; Liu, D.; Peng, Y.C.; Han, Z.J.; Zhao, C.Q.; Tang, T. Identification of transcriptome and fluralaner responsive genes in the common cutworm Spodoptera litura Fabricius, based on RNA-seq. BMC Genom. 2020, 21, 120. [CrossRef] [PubMed]

44. De Marco, L.; Sassera, D.; Epis, S.; Mastrantonio, V.; Ferrari, M.; Ricci, I.; Comandatore, F.; Bandi, C.; Porretta, D.; Urbanelli, S. The choreography of the chemical defensome response to insecticide stress: Insights into the Anopheles stephensi transcriptome using RNA-Seq. Sci. Rep. 2017, 7, 41312. [CrossRef] [PubMed] 